Int. J. Electrochem. Sci., 12 (2017) $3443-3458$

International Journal of

ELECTROCHEMICAL

SCIENCE

WWW.electrochemsci.org

\title{
Electrochemical DNA Biosensor Based on Graphene Oxide- Chitosan Hybrid Nanocomposites for Detection of Escherichia Coli 0157:H7
}

Shichao Xu ${ }^{1,2,3, *}$, Yiyi Zhang ${ }^{1}$, Kai Dong ${ }^{1}$, Junnan Wen ${ }^{1}$, Chunming Zheng ${ }^{1,2}$, Shihuai Zhao ${ }^{1,2}$

${ }^{1}$ School of Environmental and Chemical Engineering, Tianjin Polytechnic University, 399 Binshui

West Road, Tianjin 300387, China

${ }^{2}$ State Key Laboratory of Hollow Fiber Membrane Materials and Membrane Process, Tianjin

Polytechnic University, 399 Binshui West Road, Tianjin 300387, China

3 Tianjin Engineering Center for Safety Evaluation of Water Quality \& Safeguards Technology, Tianjin Polytechnic University, 399 Binshui West Road, Tianjin, 300387, China

*E-mail: xushichao@tjpu.edu.cn

doi: $10.20964 / 2017.04 .16$

Received: 12 January 2017 / Accepted: 6 February 2017 / Published: 12 March 2017

In this article, we present a simple and sensitive electrochemical DNA biosensor based on graphene oxide (GO)/chitosan (CS) hybrid nanocomposites modified glassy carbon electrode (GCE) for detection of Escherichia coli O157:H7 (E.coli O157:H7). The morphology and composition of GO and hybrid nanocomposites were characterized by transmission electron microscope (TEM), X-ray powder diffraction (XRD), field emission scanning electron microscopy (FESEM), and Fourier transform infrared spectrum (FTIR). Cyclic voltammetry investigations indicated that the GO/CS/GCE showed excellent electron transfer ability and good linear relation. Under the optimal hybridization conditions, electrochemical impedance spectroscopy (EIS) responses of ssDNA/GO/CS/GCE biosensor were in linear with the target DNA in the concentration range from $1 \times 10^{-14}$ to $1 \times 10^{-8} \mathrm{M}$ with the detection limit as $3.584 \times 10^{-15} \mathrm{M}(3 \sigma)$. Moreover, differential pulse voltammetry (DPV) studies revealed good specificity and excellent ability of ssDNA/GO/CS/GCE biosensor to distinguish complementary, 1base mismatched DNA, 2-base mismatched DNA and multi-base mismatched DNA. The developed strategy in this research revealed that the GO/CS modified electrode possess excellent performance for detecting of Escherichia coli O157:H7 DNA.

Keywords: Graphene oxide, chitosan, nanocomposites, Electrochemical DNA biosensor, Escherichia coli

\section{FULL TEXT}

(C) 2017 The Authors. Published by ESG (www.electrochemsci.org). This article is an open access article distributed under the terms and conditions of the Creative Commons Attribution license (http://creativecommons.org/licenses/by/4.0/). 